\title{
Assessment of Healthcare Facilities for the Promotion of Health Literacy - A Feasibility Study
}

\author{
Haslinger Baumann E*, Hartmann B, Daia A, Herburger AJ, Weiss C, \\ Waniek K \\ University of Applied Science, Austria
}

*Corresponding author: Elisabeth Haslinger-Baumann, University of Applied Science,

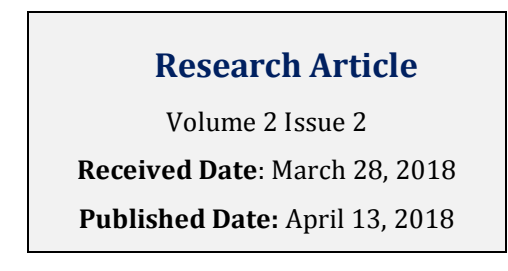
Austria, Tel: 004316066877 4015; Email: elisabeth.haslinger-baumann@fh-campuswien.ac.at

\section{Abstract}

Background: Health literacy is defined by the WHO as a "cognitive and social capacity of the individual" to "gain access to, understand and use information, to promote and maintain good health through their own motivation and ability". The strengthening of health literacy also includes people's living conditions, e.g. the environment in which information systems for orientation are available. Verbal and written guidance systems in healthcare facilities are designed differently, which can lead to anger and anxiety on the one hand, and productivity losses on the other hand. In Austria, there are no research papers on the promotion of health literacy in healthcare facilities. The aim of the present survey is to describe the orientation and guidance systems in Austrian health care facilities while examining the practicability of the survey tool.

Method: The survey tool "First Impressions \& Walking Interview" by Ruddy in the "Health Literacy Environment Activity Packet" was used. The entrance area, verbal information, orientation along the way and observation of the destination are examined. The analysis is carried out by means of a methodical triangulation. This includes a structured qualitative content analysis based on Mayring combined with quantitative elements such as the counting of positive and negative mentions.

Results: In pairs, 26 qualified nurses with several years of professional experience completed the assessment each in one of 13 healthcare facilities in Austria after a one-hour training. The results show that the entrance area is often perceived as bright and inviting, but also causes orientation uncertainties. The verbal information is usually experienced as friendly and helpful. However, the visualized control systems are often inconsistent and confusing. Frequently instances were counted, in which the labels, pictograms and guidance systems were described as not helpful; only a few positive mentions were made in which the information system was experienced as understandable, highly visible and stringent. Furthermore, German language literacy is an essential prerequisite for orientation in the healthcare institutions. 
What is required is the establishment of a professional and stringent information system in all health areas, in the design of which those affected but also all occupational groups are systematically involved.

Keywords: Health promotion; Healthcare facilities; Healthcare and nursing; Feasibility study; Health Literacy; Health communication; Feasibility Study; Workplace; Nursing

\section{Introduction}

\section{Background}

The term health literacy, in addition to basic literacy, refers to a range of skills that people need to acquire [16], understand and evaluate health information and make informed decisions that are consistent with their needs, wishes and values [1,2,7-9]. The model of health literacy is relatively new; particularly in the German-speaking area it has not yet been attached the importance required to achieve the goal of empowering all people to become health-literate citizens [10]. Nevertheless, health literacy is considered a so-called soft skill of the 21st century [11].

It is based on the premise that informed citizens can and want to adequately access information in order to make relevant decisions for themselves. According to the European Health Literacy Survey model [2], this applies to all areas of life and throughout the course of life in the fields of health promotion, disease prevention and health care in the case of an existing disease.

As in many - especially European - countries, the promotion of health literacy is a central concern of health policy in Austria. In the current government program (2013-2018), the third of the ten framework health goals is "strengthening the health literacy of the population". All people and sections of the population should be ensured low-threshold access to the information and the health care system. Particular focus is placed on the needs of disadvantaged groups (www.gesundheitszieleoesterreich.at)

In this context, for example, health care facilities such as hospitals, care facilities or outpatient clinics are called upon to shape health-promoting conditions at the organizational level. The term health literacy environment [5] has been developed for this purpose. This comprises the importance and comprehensibility of written information systems such as signs and words and verbal information sharing, as they are used for orientation in health organizations. Information systems should help people find their bearings and the right direction [12]. In the context of health, information systems are understood to be guidance and orientation systems containing health-related information. This must be found quickly and easily and understood and applied correctly. Reliable orientation through rapid comprehension of printed characters, words and letters is of great importance everywhere [3], because when people do not get their bearings in an unknown environment, feelings of insecurity, anger, helplessness or even fear arise [4]. In situations that are stressful, such as those involving one's own illnesses or emergencies, or worrying about sick relatives, these feelings of helplessness and anxiety can be amplified many times over. It can even lead to a loss of confidence in the health care facilities, or at least to very negative memories [13]. If people miss out on appointments due to poor orientation, if delays occur and planned examinations have to be postponed, the productivity and effectiveness of the institution are affected and the smooth flow of care can be hindered [11].

As early as the 1990s, planning projects in Canada showed that approximately 800 hours were spent a year in an 800-bed hospital to describe ways and provide orientation to patients, visitors, and other disoriented people [14]. This was confirmed and extended by relevant information from Germany in 2016. Schlüter [4] concludes in his analysis that 100 of a total of 1000 employees spend about 15 minutes per day only to provide directions because the existing information systems are not sufficiently clear to understand. This causes work interruptions and disturbs the general procedures so much that resulting costs in the amount of 300 euros per bed / year arise. In addition - in this calculation model - increased personnel costs amounting to about 80,000 euros arise. The cost of developing and implementing an efficient information system could reduce these costs by a third and pay for itself after three years [4]. A carefully planned, well thought-out guidance and orientation system not only contributes to the image of a healthcare facility, but also helps to reduce costs [11].

Requirements for a guidance and orientation system include seven key criteria [4]. Firstly, they refer to integrity - which means that the external and internal 


\section{Nursing \& Healthcare International Journal}

architecture, the appearance in all media, is consistent, and the mission statement in this regard is supported and lived by all colleagues. Secondly - the intuitiveness - this shows the intuitive comprehensibility by logical adaptation to spatial conditions and structures. Thirdly, it requires a reduction, that is, a minimum amount of information at maximum information content. The value, as a fourth criterion, addresses a suitable selection of durable materials, the high-quality finishing and the transparent positioning. Fifthly, guidance and orientation systems should be economically viable, that is, a standardization with a logical structure, with a limited set of signs that - as a sixth criterion - are consistent and complete from first contact to destination. Finally, accessibility as a last and seventh criterion is essential in order to provide quick, low-threshold and safe orientation to as many and as diverse people as possible [4].

Often, however, this subject only gets attention after repeated complaints in connection with the signage, or due to high stress loads of employees with regard to giving information for guidance. For guidance systems in healthcare facilities are often inconsistent and their comprehensibility requires a high level of education [3]. The authors carried out a feasibility study on "healthcompetence-friendly" environment in 10 hospitals in Spain. The aim of the study was to find out which factors inhibit or promote orientation in hospitals. The results show that the signage was perceived as hidden and badly positioned. Finding the goal-oriented path within the hospital proved difficult and confusing. The signs were inconsistent, in scientific language and without any special explanations. Positive reviews were given to the personal contacts with Security Personnel or other employees. Overall, the mean for all hospitals was 3.9 (= somewhat difficult to orient) in the 6-step scale.

In her dissertation Seumenicht [15] deals with the analysis and evaluation of guidance systems in public space. Supplying sufficient information, especially in healthcare facilities, is a challenge. Intuitive orientation of visitors within hospitals is becoming more difficult with increasing complexity. This is also the conclusion of the editorial work of Candussi, Fröhlich [16], which confirms that health-related information is often designed at a high level and requires a corresponding high level of education [16]. In hospitals, in addition to orientation difficulties, people experience feelings of anxiety due to their health situation. In addition to good and understandable signs and pictograms it is, therefore, important to establish specially trained staff to provide appropriate verbal information [15].
In a survey study $(\mathrm{n}=100)$ in the United Arab Emirates, it was found that symbols with health-specific content are less well recognized than general pictograms that are used in everyday life. However, the higher the level of education and the younger the participants, the better the comprehensibility of the presented symbols and pictograms was rated [17]. This leads to the conclusion that guidance and orientation systems are more likely to be understood by younger people who have undergone longer education.

In Austria, apart from a small preliminary study [18], no research paper has been published in which the health-competence friendliness of hospitals was assessed by means of a specific assessment. In this small study, 15 health care facilities were assessed. Once more the lack of uniformity and, to a large extent, insufficiently understandable information and guidance systems were confirmed.

Assessment tools to measure health literacy support relate to the ability to read and understand specific information in buildings for easy, individual orientation. A self-assessment tool has been developed as part of the European Health Literacy Survey (HLS-EU Survey) 20092012. Emphasis is placed on the intelligibility of the language used and the uniformity or existence of a guidance system for the blind [19]. Another building assessment tool is "The Health Literacy Environment Activity Packet First Impression \& Walking Interview" developed by Rudd [5], which was used in this study.

The aim of the present feasibility study is to use a specific assessment to analyze different healthcare facilities in terms of how comprehensible and transparent their information and guidance systems are for individual orientation. In addition, the practicability and userfriendliness of the applied assessment is tested.

\section{Method}

The "Health Literacy Environment Activity Packet First Impression \& Walking Interview" is used to assess health facilities in terms of supporting health literacy [5]. In each case, two persons assess the written and verbal information for orientation per institution. The four areas to be assessed by the "Walking Interview" include the (main) entrance / observation at the entry point or lobby, then seeking instructions / support, seeking help, then orientation - the route to a particular destination / navigation, as well as observation of the target / observation. Reflection of the Walking Interview / completes the assessment. 


\section{Nursing \& Healthcare International Journal}

The application of the quality criteria of qualitative research [6] is ensured as follows: the analysis of the performed inspections in healthcare facilities with subsequent written presentation of the observations is carried out through a text analysis based on "qualitative content analysis" with a special focus on structuring [6]. Additional quantitative recording and classification of terms $[20,21]$ supplement the evaluation. In the content analysis, written text material is assessed according to previously established procedural rules. The texts are classified according to the set categories [6,21]. Due to the fact that the results are analyzed from the application of an assessment instrument, it is already explicitly defined in advance which text passages will fall under a (main) category - the four main categories are the four observed areas (Table 1).

Subcategories are developed from the text allocated to the main categories. The text is scoured for recurrent assessments and then assigned to the mainly occurring (overall) term. Each subcategory is divided with positive and negative summaries of each of the evaluation examples. The listed summaries of the positive and negative evaluation examples are presented individually. The frequency of recurring terms is counted, which also takes into account the quantitative aspect of the analysis [20].

In a second analysis step, summarizing and counting the assessment results of all inspections consolidate the sub-categories recorded per assessment. One or two examples in the original quote that are particularly suitable for the subcategory are described as anchor examples.

In addition, a specific assessment is made to determine the applicability / practicability of the survey tool after use. This rating is carried out on a scale of 1 to 5: 1 very practical - 5 not practical.

\section{Ethical Reflection}

Compliance with the principles of ethical research according to the Belmont Report or the Helsinki Declaration (http://www.hhs.gov/ohrp/) has been ensured by a sensitive inspection mode that was neither noticeable nor disturbing. The focus of the assessing persons was exclusively on the orientation and guidance systems of the buildings and no other people were addressed except for appointed respondents. The inspected healthcare organizations were pseudonymized for the entire analysis in order not to be able to draw any conclusions about the specific places.

\section{The Survey Instrument}

The survey instrument "First Impressions \& Walking Interview" [5] is divided into two parts. The first part refers to the first impression provided by the assessed healthcare organization on the Internet, by telephone contact and in the immediate external environment of the building, especially on the way to the entrance of the building.

The second part "Walking Interview" refers to the assessment of different areas within the building (Table1).

The first focus is the main entrance. Here, the design of the entrance area should be assessed, the general orientation possibilities and the visibility and comprehensibility of the information.

The second focus is on finding directions / support. The general placement of the information desk is assessed. When asking for the way to a particular institute or ward, the informing person is judged on the type, manner and intelligibility of the information received. The aim is to note, which impression regarding verbal information is created in general.

The third focus is orientation - the way to a specific target. The design of the way with regard to signage, uniformity of the guidance system as well as the visibility, positioning and comprehensibility of signs / writing / pictograms are examined.

The next focus is the observation of the target. It is estimated to what extent the process of further registration is clearly visible and understandable and whether features for wellbeing have been created.

Finally, a general reflection on the entire inspection of the building is carried out. All the impressions gained are exchanged and transcribed in the form of minutes. 


\section{Nursing \& Healthcare International Journal}

\begin{tabular}{|c|c|c|c|c|}
\hline $\begin{array}{c}\text { Observation at the entry } \\
\text { point or Lobby }\end{array}$ & $\begin{array}{c}\text { Seeking } \\
\text { directions/help }\end{array}$ & $\begin{array}{c}\text { Orientation-the way } \\
\text { to a particular } \\
\text { target/navigation }\end{array}$ & $\begin{array}{c}\text { Observation of the } \\
\text { target }\end{array}$ & $\begin{array}{c}\text { Reflection on } \\
\text { the Walking } \\
\text { Interview }\end{array}$ \\
\hline $\begin{array}{c}\text { Assessment of the general } \\
\text { design and impression of } \\
\text { the entrance area Analysis } \\
\text { of orientation possibilities. } \\
\begin{array}{c}\text { Visibility and } \\
\text { comprehensibility of } \\
\text { information. }\end{array}\end{array}$ & $\begin{array}{c}\text { Analysis of } \\
\text { information desk. } \\
\text { Assessment of } \\
\text { verbal information } \\
\text { regarding type, } \\
\text { manner and } \\
\text { intelligibility of } \\
\text { information } \\
\text { received. }\end{array}$ & $\begin{array}{c}\text { Analysis of the guidance } \\
\text { system. Analysis of } \\
\text { orientation signs - } \\
\text { existence, uniformity. } \\
\text { target. }\end{array}$ & $\begin{array}{c}\text { Transparency of the } \\
\text { process of further } \\
\text { registration, } \\
\text { information } \\
\text { transfer of involved } \\
\text { people }\end{array}$ & $\begin{array}{c}\text { Final } \\
\text { discussion and } \\
\text { reflection on } \\
\text { impressions } \\
\text { gained }\end{array}$ \\
\hline
\end{tabular}

Table 1: Survey instrument: Walking Interview [4].

The instrument is used in pairs. In this case, a person is the leader who decides on a way and finds it. The second person goes along, mainly observing, continually formulating impressions, or writing them down in keywords.

All questions of the Walking Interview are open-ended questions. There are no predefined response categories. Open answers and descriptions are welcome.

\section{Results}

In May 2016, 26 health and nursing staff estimated in pairs a total of 13 health care facilities in eastern Austria. 11 hospitals, a nursing home and a rehabilitation facility in eastern Austria were inspected. All assessors were given a one-hour training course on how to handle the instrument. The healthcare organizations could be chosen freely. Each focus was analyzed according to the aspects stated in the assessment. On average the entire walk took 30 minutes. Table 2 summarizes the main results of the assessments. The four estimated ranges are each divided into positive (+) and negative $(-)$ attributes. The developed and condensed subcategories are similar per main category, but ranked differently and with different focus points according to the manner and frequency of the individual mentions.

\section{First Main Category: Observation at the Entry Point or Lobby}

In the main category "Entrance area" 4 subcategories could be worked out, whereby 2 of them were assigned a further subcategory in order to be able to present the results more precisely and specifically. In the first subcategory of facilities, infrastructure, equipment, the healthcare institutions were considered to be very good, since the design of the entrance area with seating, escalators, elevators and various business premises (25 mentions) meets the different needs and expectations of visitors, patients and employees. In contrast, the absence of seating or trashcans was detected only twice.

The second subcategory atmosphere, which includes "lighting, lighting conditions" as a further subcategory, was rated relatively balanced with 20 positive and 27 negative mentions. When describing the first impression and the mood after entering the entrance area adjectives were used such as inviting, clean, friendly and pleasantly illuminated. The presence of daylight was highlighted 3 times. In the case of the negative mentions, the atmosphere was described as cool, impersonal, unwelcoming and dark. A very clear discrepancy between "helpful" and "confusing" was found in the third subcategory information system for general orientation. There were 39 mentions in which the labels, pictograms and guidance systems were described as not helpful, and only 7 positive mentions, in which the information system was experienced as clear, understandable and clearly visible.

The fourth subcategory accessibility, which includes the subcategory "language", also produced a clear result (11 positive and 27 negative). For example, the fact that the signs and directions for orientation are often only available in one language (German) was considered a barrier. The lack of a guidance system for the blind or a tactile guidance system as well as the passing of revolving doors was also considered a barrier for people with special needs. Positive features are the existence of barrier-free toilets and the possibility of wheelchair access to the healthcare facility by lift, ramp or sidewalk. 


\section{Nursing \& Healthcare International Journal}

\begin{tabular}{|c|c|c|c|}
\hline Main category & Subcategory & & $\begin{array}{l}\text { Overall mentions } \\
\end{array}$ \\
\hline \multirow{4}{*}{$\begin{array}{l}\text { Observation at the entry } \\
\text { point or lobby }\end{array}$} & $\begin{array}{c}\text { Facilities, infrastructure, } \\
\text { equipment }\end{array}$ & & \multirow{4}{*}{$\begin{array}{l}63 \text { positive, e.g.good infrastructure; } \\
\text { pleasant lighting / daylight, barrier-free } \\
\text { access, sidewalks, lifts, ramps. } \\
95 \text { negative, e.g. atmosphere cold, } \\
\text { impersonal, not welcoming; small signage, } \\
\text { unfavorable positioning, German literacy } \\
\text { as precondition; lack of guidance system } \\
\text { for the blind and tactile guidance system }\end{array}$} \\
\hline & Atmosphere & $\begin{array}{l}\text { Lighting, lighting } \\
\text { conditions }\end{array}$ & \\
\hline & $\begin{array}{l}\text { Information system for } \\
\text { general orientation }\end{array}$ & & \\
\hline & Accessibility & Language & \\
\hline \multirow{3}{*}{ Directions, seeking help } & Facilities, equipment & & \multirow{3}{*}{$\begin{array}{l}39 \text { positive, e.g. presence of information } \\
\text { desk; friendly first contact; good, } \\
\text { understandable information transfer. } 23 \\
\text { negative, e.g.no respondent present; } \\
\text { information desk not adjusted to needs of } \\
\text { wheelchair users. }\end{array}$} \\
\hline & $\begin{array}{c}\text { Making contact, } \\
\text { atmosphere }\end{array}$ & $\begin{array}{l}\text { Giving information, } \\
\text { giving directions }\end{array}$ & \\
\hline & Accessibility & & \\
\hline \multirow{4}{*}{$\begin{array}{l}\text { Orientation - the way } \\
\text { to a specific } \\
\text { destination/navigation }\end{array}$} & Atmosphere & $\begin{array}{l}\text { Lighting, lighting } \\
\text { conditions }\end{array}$ & \multirow{4}{*}{$\begin{array}{c}87 \text { positive, e.g. good infrastructure; } \\
\text { facilities; accessibility adjusted to older } \\
\text { and walking impaired } \\
91 \text { negative, e.g. German literacy as } \\
\text { precondition; bleak atmosphere, bare, } \\
\text { oppressive color scheme, bad design, small } \\
\text { signage, confusing, unfavorable } \\
\text { positioning }\end{array}$} \\
\hline & Accessibility (corridor, lift) & & \\
\hline & $\begin{array}{c}\text { Facilities, infrastructure, } \\
\text { equipment }\end{array}$ & & \\
\hline & $\begin{array}{l}\text { Information and guidance } \\
\text { system (corridor, lift) }\end{array}$ & & \\
\hline \multirow{5}{*}{$\begin{array}{l}\text { Observation of the } \\
\text { destination }\end{array}$} & Information system & & \multirow{5}{*}{$\begin{array}{l}23 \text { positive, e.g. good infrastructure, } \\
\text { facilities; inviting, cozy atmosphere; color } \\
\text { marking of the guidance systems as } \\
\text { enrichment. } \\
48 \text { negative, e.g. lack of personnel; lack of } \\
\text { information regarding procedures; } \\
\text { absence or lack of signage or confusing } \\
\text { signage }\end{array}$} \\
\hline & First contact & $\begin{array}{l}\text { Giving information } \\
\text { and directions }\end{array}$ & \\
\hline & Accessibility & & \\
\hline & Facilities, infrastructure & & \\
\hline & Atmosphere & Lighting & \\
\hline
\end{tabular}

Table 2: System of categories.

\section{Second Main Category: Instructions / Seeking Help / Directions}

The main category "Instructions / support" could only be divided into 3 subcategories. In the first subcategory of facilities, equipment mainly the presence, but also the labeling of information switches, where the desired information could be obtained, was described (mentioned 13 times). Only twice was the insufficient labeling of the information office criticized (Table 2).

The second subcategory first contact, atmosphere contains the subcategory "Giving information, giving directions", in which the quality of the information transfer was assessed.

The 23 positive ratings describe a friendly, helpful and attentive appearance of the respondent, who understandably describes the way to the desired destination (mentioned 4 times). A negative mention was made of non-continuous presence of the respondent or an answer spoken too fast (altogether 16 negative mentions).

The third subcategory of accessibility describes both physical and language barriers. The 5 of the total of 6 negative mentions refer to an inappropriate height of the information desk for wheelchair users, which makes it difficult to establish contact. The sixth negative mention describes a possible language barrier due to information provided in dialect, which requires special language skills.

The 3 positive mentions include well-accessible information desks (mentioned twice) and staff members who give verbal or non-verbal information by showing (mentioned once).

In summary, it can be said that the verbal transmission of information is mostly experienced as friendly and helpful. The optical orientation systems, however, are often confusing and designed too small, not mounted visibly and also require literacy in the German language. 


\section{Nursing \& Healthcare International Journal}

\section{Third Main Category: Orientation - The Way to a Specific Destination / Navigation}

When experiencing the atmosphere as the first defined subcategory of the main category "Orientation", "Lighting and the lighting conditions" play a major role with $9+/$ 19 - mentions (total of 12 mentions $5+/ 7$ - mentions) (Table 2); they constitute a separate subcategory within the category atmosphere. In addition, the color scheme (a total of six mentions) was particularly highlighted with "the corridors seem bleak: lack of warm or intense color concept" and the room size (a total of 5 mentions), "wide, enough space, pleasant atmosphere". This subcategory also describes the decoration, the design and the overall impression of the corridors, which altogether create a rather negative image. When examining the second defined subcategory of accessibility in the corridor $(18+/ 19$ - mentions $)$ and in the lift $(12+/ 9$ - mentions), the main focus is on walking disability (a total of 42 mentions). Remarkable is the observation of the door systems with a total of 12 mentions, whereby on the one hand it is determined that these systems have a negative influence on barrier-free movement, "the door opens quickly to the outside, which can even be dangerous for wheelchair users". In the lift, the presence of audible signals is perceived as positive for the visually impaired (total of 5 mentions). The strong dominance of the German language is also recorded as a barrier (6 mentions).

The third sub-category Facilities-infrastructureequipment $(7+/ 2$ - mentions) covers seating facilities, the presence of plants and the possibility to get snacks. This category can be clearly rated as positive. The heart of the analysis is the evaluation of the fourth subcategory Information and guidance systems. Like the second sub-category accessibility, this category was examined separately in the corridor $(36+/ 35$ - mentions) and in the lift / elevator ( $3+/$ 8-mentions). A total of 19 positive assessments were made in terms of visibility and efficiency of signage, for example: clear, noticeable, adequate, consistent, helpful, purpose-oriented, repetitive, clear, etc.; seven negative reviews:" changing, not uniform, confusing, not immediately visible etc."It seems particularly relevant where the signs and other guidance systems are placed ( $9+/ 7$ - mentions): "signs at eye level "or sign from the ceiling:" not immediately noticeable ". Of course, an adequate font size is supportive (6 positive answers). Color markings are seen as enrichment for orientation (5 positive mentions), which is probably because they are self-explanatory and easy to follow. Furthermore, floor markings and pictograms (3 entries) are orientation promoting. From the interviews, it can be seen that the main shortcoming of the guidance systems is the inadequate placement of the signs (7 mentions), "small signs above head height" or that they are not uniformly marked (5 mentions), "changing orientation signage, not uniform in the corridor "or also because signs are not present at all (4 mentions),"information board or site plan not available ". With regard to guidance systems in the lift, a clear definition of the direction of travel is clearly welcome: "arrows on the buttons with` I want to go '-these arrows point up or down "or "Whether the lift is going up or down, is indicated by small arrows above the lift doors. However, if you do not know that, you can lose some time".

\section{Fourth Main Category: Observation of the Destination}

In the main category "Observation of the destination" a total of 5 subcategories was formed. In order to allow an even more precise characterization of the categories, 2 of the subcategories are each assigned a further subcategory (Table 2).

The first relevant subcategory information system has the same number of positive and negative evaluations: 15 + / 15 - mentions were counted. Of the 15 negative remarks, six refer to a missing signage of the target area: "No indication of the target, found by accident". Inadequate or confusing signage was stated four times: "many ambiguous signs". Three of the mentions describe an inappropriate size of the labeling.

The second relevant subcategory of First contact shows a rather negative picture. In the destination area this category was rated positive only twice and negative 7 times. In 5 mentions of the 7 it is stated that a contact was not possible because no staff was present: "information desk unoccupied". The actual contact was otherwise experienced twice positive and negative respectively. In this case it is more a question of the welcoming staff, their friendliness or dismissive reactions: "The employees greeted in a friendly way, but they did not appear to be disturbed in their work routine by the inspecting people" and "calling caregiver does not greet, does not introduce himself/herself, does not appear very cordial."If the defined subcategory "giving information and directions" is mentioned, it is rather positively recorded. 8 mentions represent the positive perceptions, whereby 2 refer to the existence of a written form of information. The others describe the verbal information transfer as uncomplicated, precise, understandable, clear, explicit or friendly: "time is taken for the conversation". 5 entries 


\section{Nursing \& Healthcare International Journal}

were qualified as negative, 4 of which described the lack of a written form of instruction and information: "no information regarding the procedure of registration, required documents". All in all, it can be said that verbal information is generally perceived as friendly, uncomplicated and nice, but written information is lacking.

The third subcategory accessibility shows a very balanced picture: 8 positive and 8 negative mentions, two of each referring to the language barrier. This subcategory mainly identifies the needs of older people and those with disabilities, describing handrails, anti-slip floor coverings and the overall accessibility of the destination. With regard to negative issues, an adequate guidance system for the blind or deaf people is missing. Concerning language barriers, the strong dominance of the German language is noted.

The fourth subcategory equipment and infrastructure can clearly be assessed positively through the presence of seating, distractions and other facilities to meet the needs of patients. Here, 19 entries are positive and only 4 negative.

The fifth and final subcategory atmosphere also tends to be perceived as positive; there are 17 positive responses compared to 12 negative responses. Here the impressions and the mood are mentioned, such as inviting, comfortable, well structured or friendly. The subcategory atmosphere has "lighting" as a subcategory, whereby brightness is perceived as particularly positive ( 6 positive, 2 negative mentions).

\section{Assessment of the Practicability of the Survey Instrument}

Finally, the 26 assessors participated in the evaluation of the applicability / practicality of the survey tool. The assessment was made on a scale of 1 to 5 . According to the school grading system 1 is considered very practicable - 5 not practicable. Furthermore, the persons were asked to justify their classification. 6 answers refer to $1=$ very practicable, three more to 2 , practicable. Only one person ranked the survey instrument at level 3, moderately practicable. There were no assessments at levels 4 and 5 (not practical). The justifications for the classifications referred to the clarity of the questions in the instrument and to the fact that this trains and encourages a professional view (4 mentions) and a comprehensive perspective ( 3 mentions). Additionally, the inspection in pairs is perceived as very beneficial ( 3 mentions).

\section{Discussion and Conclusion}

The objective of this feasibility study, i.e. providing a summary of the Health Literacy Friendliness of healthcare facilities (hospitals, nursing home, rehabilitation facility) while assessing the practicability and user-friendliness of the instrument, could be achieved. The used instrument "The Health Literacy Environment Activity Packet First Impression \& Walking Interview" depicts the relevant aspects of orientation in healthcare facilities.

In summary, the assessment of the individual facilities confirms the inconsistency in the information and guidance systems $[3,4,18]$. This inconsistency extends over the entire inspected areas of main entrance, corridor systems and destination of the inspection, but is evident to varying degrees. At the same time, it is apparent that individual hospital operators have already recognized and implemented the importance of uniform information and orientation systems. This is in line with a mission statement based on the fact that a unified system is needed for clear communication that has to include the entire organization $[4,15,22]$.

The healthcare facilities assessed in this study are generally easy to use, both in terms of infrastructure and equipment, in the entrance area as well as at the destination. For a positive atmosphere, light and color schemes as well as the room size appear important. Restrictively, the entrance area is often perceived as "stressful" due to shopping facilities, seating arrangements and the amount of people. However, with regard to the orientation systems on the way to a destination, the assessments are predominantly critical. Optical signs and information signs are perceived as confusing, hidden and not well recognizable or not helpful. Above all, they require literacy in the German language. Unsystematic and not uniformly used, the color markings are sometimes seen as restricting orientation, as are the inconsistent and patchy floor markings and pictograms. In terms of accessibility for people with special needs, there are often obstacles such as revolving doors, carpets or difficult access through a non-accessible height of signs. Also for blind or visually impaired people, the majority of the healthcare facilities seem to be inadequately equipped in terms of the lack of tactile or acoustic guidance systems.

The first contact and the verbal information transfer at the information desk in the entrance area are consistently perceived as positive. The informing persons are often experienced as friendly, competent and helpful. This 


\section{Nursing \& Healthcare International Journal}

contributes to a positive mood and increases the feeling of being welcome.

In order to create an environment that promotes health literacy, further adaptation of the systems is important so that all persons acting in it can make decisions based on orientation on the one hand, and, with additional information (such as brochures, posters, information screens), in line with their wishes and values [7]. This is also confirmed in the expert survey by Hartmann [11]. Accordingly, the requirements for a consistent guidance and orientation system are: logical, intuitive, and consistent. In a nutshell, this means that the visual, content-related and graphic design of guidance and orientation systems influences the users' health literacy, i.e. that they interact with each other. This means that the development of guidance and orientation systems should therefore be carried out by professional planners [11]. In the present study this can be corroborated by the fact that the assessing persons repeatedly point to moments triggering positive feelings, which are evoked by consistent, comprehensible guidance and orientation systems, and at the same time describe the negative feelings, which cause confusion, insecurity and helplessness through unclear signals. In situations of heightened sensitivity and illness, as is the case with a visit to a hospital, such situations can be particularly stressful [4] and even trigger crises. Especially in emergency situations, such crises are highly dramatic for all concerned, since regulatory mechanisms can no longer be accessed.

Limitations of this implementation study are that the results were obtained by means of a random sample and are not representative. Another limitation is the assessment by trained health and nursing professionals with several years of professional experience in hospitals. These people know healthcare organizations very well and know how they function. The appraisers were asked to take a distanced, investigative attitude in order to make the assessment as neutral as possible. Although the inspections were not carried out in their own work areas, it cannot be completely ruled out that many years of work in the health sector may have impacted the assessment either in terms of overlooking barriers or making a particularly critical assessment. In the future, other groups, such as e.g. persons depending on aids (such as wheelchairs, walkers) or persons with little to no education or persons without hospital experience will systematically be involved in these assessments.

In terms of the assessment tool itself, the individual questions are openly formulated and little operationalized. There are also no predefined response categories. Therefore, no standardized statistical analysis tests were used. The results were developed from the written attributions using the qualitative method [23] and counts [20]. This way of assessing offers the opportunity to comprehensively consider and reflect on many aspects. Also, the inspection in pairs and joint reflection were useful. The qualitative evaluation of the written minutes can adequately address these extensive results. So far no test-theoretical investigations on reliability and validity of the assessment tool have been carried out. In the future, an operationalization of the questions could be considered, or a ranking of the answer options could be developed.

The evaluating health and nursing staff attest to the instrument's high practicability, comprehensibility and good applicability. Basically, the resulting perspective change was experienced as interesting and instructive. The assessors experienced situations which usually only patients or visitors face. In this context employees are usually the respondents. In healthcare organizations (and not only there) a lot of time is spent on giving information for orientation [4], which would be better used in direct care and nursing. Therefore, all affected professional groups should be involved as early as possible in the planning and design of information systems [11]. On the one hand, this can have a positive effect on the productivity of care, on the other hand it increases the satisfaction of all those involved. As the individual orientation based on a clear, uniform and consistent information management in the inclusive design, in relation to the different levels such as electronic, verbal, written and tactile, triggers positive feelings, and these in turn promote health.

\section{Conclusion}

For the establishment of a comprehensive information system in the health sector developed by specialist planners, an early involvement of all occupational groups, especially health care and nursing staff as the largest occupational group that works most extensively with those affected, is inevitable. An information system that tends to be barrier-free conveys quality, security and reliability, which in turn generate trust - and trust in the healthcare system is of enormous importance for individual health.

\section{References}

1. WHO (2009) Health Promotion, Track 2 Health literacy and health behavior. World Health Organization. 


\section{Nursing \& Healthcare International Journal}

2. Sørensen K, Van den Broucke S, Fullam J, Doyle G, Pelikan J, et al. (2012) Health literacy and public health: A systematic review and integration of definitions and models. BMC Public Health 12: 80.

3. Grone R, Rudd R (2011) Results of a feasibility study to assess the health literacy environment: Navigation, written, and oral communication in 10 hospitals in Catalonia, Spain. In: Journal of Communication in Healthcare 4(S): 227-237.

4. Schlüter G (2016) Verlaufen unmöglich) - Moderne Wegeleit- und Orientierungssysteme im Krankenhaus. In: Pfannenstiel M, Rasche C, Mehrlich $\mathrm{H} \quad(\mathrm{Hg}) \quad$ (Eds.), Dienstleistungsmanagement im Krankenhaus. Nachhaltige Wertegenerierung jenseits der operativen Exzellenz. Springer Gabler, Wiesbaden S: 333-362.

5. Rudd R (2010) The Health Literacy Environment Activity Packet First Imprssion \& Walking Interview. Online resource.

6. Mayring $P$ (2002) Einführung in die qualitative Sozialforschung, 5. Auflage, Beltz Verlag, Weinheim, Basel.

7. Sladek U, Groth S (2013) Angebote zur Förderung von Gesundheitskompetenz in Österreich. Eine Erhebung im Rahmen des Projektes Health Literacy - Vertiefen - Vernetzen - Verankern des Bundesministeriums für Arbeit, Soziales und Konsumentenschutz, Wien.

8. Berkman ND, Sheridan SL, Donahue KE, Halpern DJ, Crotty K (2011) Low health literacy and health outcomes: an updated systematic review. Ann Intern Med 155(2): 97-107.

9. Soellner R, Huber S, Lenartz N, Rudinger G (2010) Facetten der Gesundheitskompetenz-eine Expertenbefragung. Zeitschrift für Pädagogik 56: 104114.

10. Vogt D, Messner M, Quenzel G, Schaeffer D (2015) "Health Literacy"-ein in Deutschland vernachlässigtes Konzept? Springer-Verlag 11(1): 46-52.

11. Hartmann B (2017) Gesund.Orientiert.Kompetent. Gesundheitskompetenzförderliche Leit- und Orientierungssysteme in Gesundheitseinrichtungen und die Rolle der professionellen Pflegeberatung. Masterthesis an der Fachhochschule Campus Wien.
12. Braun V (2004) Leit- und Orientierungssysteme in Bibliotheken:

13. Kucera M (2016) Wegbegleiter und Aushängeschild. In: Kma - Das Gesundheitswirtschaftsmagazin 16: 4649.

14. Arthur P, Passini R (1992) Way finding - People, Signs and Architecture, McGraw-Hill Book Co, Toronto.

15. Seumenicht N (2009) Analyse und Bewertung vorhandener Leitsysteme zur Entwicklung von Gestaltungsempfehlungen für innovative, intuitive und sichere Leitsysteme in öffentlich zugänglichen Gebäuden am Beispiel Einkaufszentrum. Dissertation an der Universität Duisburg-Essen.

16. Candussi K, Fröhlich W (Hrsg.) (2015) Leicht lesen: Der Schlüssel zur Welt, Böhlau Verlag.

17. Hashim MJ, Alkaabi MS, Bharwani S (2014) Interpretation of way-finding healthcare symbols by a multicultural population: Navigation signage design for global health. Appl Ergon 45(3): 503-509.

18. Haslinger-Baumann E (2016) Einschätzung von Gesundheitseinrichtungen bezüglich Förderung der Gesundheitskompetenz - $\quad$ Eine Durchführbarkeitsstudie. In: Tagungsband zum 10. Forschungsforum der österreichischen Fachhochschulen, Fachhochschule des BFI Wien GmbH, pp: 1-8.

19. Pelikan J, Röthlin F, Ganahl K (2015) HLS-EU Consortium: Comperative Report on Health Literacy in Eight EU Member States. The European Health Literacy Survey HLS-EU.

20. Polit D, Beck Ch, Hungler B (2004) Lehrbuch Pflegeforschung. Methodik, Beurteilung und Anwendung. Verlag Hans Huber, Bern.

21. Lamnek S (2005) Qualitative Sozialforschung, Lehrbuch, 4. Auflage, Beltz Verlag, Weinheim Basel.

22. Wong B (2012) Building a Health Literate Workplace. Workplace Health \& Safety 60(8): 363-369.

23. Mayring P (2010) Qualitative Inhaltsanalyse. Grundlagen und Techniken. 11. Aktualisierte und überarbeitete Auflage, Beltz Verlag, Weinheim Basel. 